\title{
Erratum to: Plant Communities, Soil Carbon, and Soil Nitrogen Properties in a Successional Gradient of Sub-Alpine Meadows on the Eastern Tibetan Plateau of China
}

Wen-Jin Li • Jin-Hua Li • Johannes M. H. Knops •

Gang Wang $\cdot$ Ju-Jie Jia $\cdot$ Yan-Yan Qin

Published online: 9 January 2010

(C) Springer Science+Business Media, LLC 2010

Erratum to: Environmental Management

(2009) 44:755-765

DOI 10.1007/s00267-009-9361-1

Unfortunately, in page 757 in the original publication, under the Section "Study Design" the sentence in the second paragraph is incorrectly published. The sentence should read "The fields used in this study were set aside from agriculture in 2002, 2000, 1998, 1988, and 1973, then had an age since abandonment at sampling time of 1, 3, 5, 15 , and 30 years."

The online version of the original article can be found under doi:10.1007/s00267-009-9361-1.

W.-J. Li · J.-H. Li ( $₫)$ · G. Wang · J.-J. Jia · Y.-Y. Qin Key Laboratory of Arid and Grassland Agroecology, Lanzhou University, Lanzhou 730000, People's Republic of China e-mail: lijinhuap@sohu.com

W.-J. Li

e-mail:wenjinli@yahoo.com.cn

J. M. H. Knops

School of Biological Sciences, University of Nebraska,

348 Manter Hall, Lincoln, NE 68588-0118, USA 